\title{
Ambientalización curricular. El covid-19, nuevos énfasis para la educación
}

María Teresa Bravo Mercado ${ }^{10}$

Universidad Nacional Autónoma de México, México

Autor de correspondencia: 'teresabm@unam.mx Recibido: 17 de julio de 2020 Revisado: 10 agosto de 2020 Aprobado: 12 de diciembre de 2020 Publicado: 26 de enero de 2021

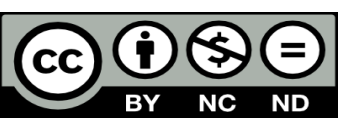

\section{Resumen}

La ambientalización curricular ha sido promovida desde el campo de la educación ambiental para la formación ambiental - con criterios de sustentabilidad- de las futuras generaciones que desarrollarán las prácticas profesionales para las que han sido formados. Las instituciones de educación superior se consideran agentes de cambio social que aportan soluciones a problemas sociales críticos y forman a los futuros profesionales. Sin embargo, juegan un papel paradójico, porque, en buena medida, han contribuido a la generación de los problemas ambientales y de insostenibilidad. Se ha propuesto examinar críticamente el tipo de formación profesional que ha sido promovida desde las universidades, a fin de refrendar su compromiso con el cuidado y el mantenimiento de las propiedades ecosistémicas de la naturaleza. En el presente trabajo, se hace un recuento sintético de las orientaciones de la ambientalización curricular antes de la pandemia del covid-19. Se desarrollan algunas aproximaciones sobre la aparición del coronavirus en la vida de los seres humanos. Debido a ello, las orientaciones que ahora está adquiriendo el trabajo de la ambientalización curricular presentan nuevos énfasis en la problemática ambiental para los espacios educativos.

Palabras clave: ambientalización curricular, currículum ambientalizado, coronavirus, educación ambiental, educación superior, crisis ambiental

Para citar este artículo: Bravo, M. (2021). Ambientalización curricular. El Covid-19, nuevos énfasis para la educación. Praxis \& Saber, 12(28), e11468. https://doi.org/10.19053/22160159. v12.n28.2021.11468 


\title{
Curricular environmentalization. Covid-19, new emphases for education
}

\begin{abstract}
Curricular environmentalization has been promoted from the field of environmental education for environmental training-with criteria to ensure the sustainability-of future generations that will carry out the professional practices for which they have been trained. Higher education institutions are considered agents of social change, providing solutions to critical social problems and training future professionals. However, they play a paradoxical role because, to a large extent, they have contributed to the emergence of environmental problems and unsustainability. It has been proposed to critically assess the type of professional training that has been promoted by the universities, in order to corroborate their commitment to the care and maintain the ecosystem properties of nature. In this article, we provide a summary of the directions of curriculum environmentalization before the Covid-19 pandemic. Some views on the appearance of the coronavirus in the life of human beings are discussed. Because of that, the directions now being followed in the context of curriculum environmentalization feature new emphases on environmental problems for educational spaces.
\end{abstract}

Keywords: curriculum environmentalization, environmentalized curriculum, coronavirus, environmental education, higher education, environmental crisis

\section{Ambientalização curricular. A Covid-19, novas ênfases para a educação}

\section{Resumo}

A ambientalização curricular foi promovida a partir do campo da educação ambiental para a formação ambiental - com critérios de sustentabilidade - das gerações futuras que desenvolverão as práticas profissionais para as quais foram capacitadas. As instituições de ensino superior são vistas como agentes de mudança social, fornecendo soluções para problemas sociais críticos e formando futuros profissionais. No entanto, eles desempenham um papel paradoxal, pois, em grande medida, têm contribuído para a geração de problemas ambientais e insustentabilidade. Tem sido proposto examinar criticamente o tipo de formação profissional promovida nas universidades, a fim de corroborar seu compromisso com o cuidado e a conservação das propriedades ecossistêmicas da natureza. Neste artigo, é feito um relatório sintético das orientações da ambientalização curricular antes da pandemia da Covid-19. São desenvolvidas algumas aproximações sobre o aparecimento do coronavírus na vida dos seres humanos. Por causa disso, as orientações que o trabalho de ambientalização curricular está adquirindo apresentam agora novas ênfases da problemática ambiental para os espaços educacionais.

Palavras-chave: ambientalização do currículo, currículo ambientalizado, coronavírus, educação ambiental, educação superior, crise ambiental 
La crisis ambiental contemporánea ${ }^{1}$, desde sus orígenes, ha seguido un proceso creciente en cuanto a su ritmo, magnitud, nivel y profundidad (Tommasino et al., 2001). Ha transitado por preocupaciones meramente ecológicas hasta inquietudes por la afectación en todas las esferas de la vida humana y no humana. Su creciente profundidad ha hecho que se reposicione en el entramado social y ocupe uno de los principales ejes para comprender y perfilar los nuevos contornos del mundo y del desarrollo tanto de las presentes como de las futuras generaciones a nivel mundial.

Podemos comprender la génesis de la crisis ambiental en el entramado de múltiples desajustes de la articulación entre la sociedad con la naturaleza. Morín y Kern (1993) señalan el desajuste económico mundial, el desajuste demográfico y la crisis del desarrollo, a lo que se suma el desajuste ambiental. Por lo anterior, Toledo (1996) y Alba (1991) señalan que vivimos una crisis societal, de civilización o crisis social generalizada. Dicha crisis muestra el derrumbe de estructuras económicas, políticas, culturales, éticas, educativas, ideológicas, sociales, ambientales y de configuraciones sociales anteriores. Esto evidencia un proceso de cambio hacia otros derroteros, hacia otras estructuras y otras prácticas sociales que aún se encuentran en formación. Sin embargo, el proceso de configuración de las nuevas sociedades se da en un marco de mayor precariedad y, para países como el nuestro - del tercer mundo-, las nuevas condiciones nos son más adversas.

Desde el campo ambiental ${ }^{2}$ se han perfilado perspectivas de solución, modelos de desarrollo, orientaciones ambientales y de sustentabilidad, a fin de revertir y superar el profundo deterioro de la naturaleza que se presenta a nivel nacional y mundial. En esta gran empresa se ve la educación superior como una de las instituciones sociales de trascendencia en la actual configuración mundial, por lo que su vinculación profunda con las causas ambientales es imperativa.

La educación superior es, con mayor énfasis, un sector estratégico para el desarrollo de las sociedades. En el contexto de la llamada sociedad de conocimiento, el saber y las instituciones ligadas a él reconfirman la singularidad e importancia de las instituciones de educación superior [IES]. Si bien las IES son instituciones históricas ${ }^{3}$, a su vez pretenden responder a su tiempo, espacio, entorno y exigencias sociales, lo que en la actualidad las ha convertido en instituciones de gran complejidad que tienen una gran trascendencia en el presente y para el futuro.

Son instituciones en donde se transmite y, en una buena parte de ellas, se crea el saber y se certifica. Las IES se extienden más allá de sus fronteras. Su labor no termina en sí mismas. A través de sus egresados, de su trabajo educativo e investigativo, de sus profesores y de sus investigadores, se extienden a la sociedad y alcanzan su sentido y su concreción ante ellas mismas. Por ello, varios investigadores han señalado el papel de las IES como de importancia estratégica para la sustentabilidad de las sociedades, con la esperanza de que contribuyan con los objetivos de cambio ambiental.

\footnotetext{
1 Nos referimos a la crisis que se desarrolló a partir de la Revolución industrial, pero que se ha recrudecido desde las postrimerías de la Segunda Guerra Mundial, en la que la relación de los seres humanos con la naturaleza no se había presentado en la historia ambiental del mundo, al trastocar los equilibrios dinámicos de esta.

2 Se ha denominado campo ambiental al conjunto de actores, programas y políticas que desde el sector gubernamental, educativo o social atienden la cuestión ambiental, cada uno desde sus propios espacios, pero vinculados a través de debates, polémicas y acuerdos.

3 Las IES, particularmente las universidades, surgieron en el siglo XI en Europa con antecedentes de las escuelas catedrales. En México aparecen en el siglo XVI en la época colonial.
} 
Sin embargo, la educación superior tiene que repensarse y reconceptualizarse, ya que es heredera de visiones antropocéntricas y mecanicistas que han contribuido a la crisis ambiental contemporánea. La visión de las relaciones entre la sociedad y la naturaleza ${ }^{4}$ - particularmente las formas simbólicas de acercamiento al mundo natural- ha sido determinante para generar la crítica situación ambiental. En ello ha contribuido básicamente la visión mecanicista del mundo que se constituyó desde hace tres siglos.

El mecanicismo impregnó por completo la forma de vida de la sociedad occidental y, por ende, de la educación superior. Esto trajo dos consecuencias: el materialismo - al pensar que solo existe lo material, lo objetivo- y el determinismo - desde la idea de que todo tiene una causa física, incluso la conciencia-. La visión mecanicista implica la fragmentación del conocimiento y, con ello, la parcelación de la realidad en disciplinas o campos del saber. Esta visión ha sido central para interpretar e intervenir la realidad, ya que la biosfera ha sido fragmentada y desestructurada, lo cual es contrario a un enfoque que quería ser estructurante e integrador. La ciencia moderna que suscribe esta visión ha sido uno de los instrumentos más poderosos para el manejo y transformación del medio natural. La universidad, a través de sus tareas centrales, particularmente de la formación de profesionales, ha sido portadora de estas visiones atomizadas.

Sin embargo, la crisis ambiental ha generado nuevos conocimientos y saberes, que se separan del paradigma mecanicista, a través de estrategias conceptuales orientadas hacia la construcción de una nueva racionalidad social y epistemológica, guiada por principios de democracia, sustentabilidad ecológica, diversidad cultural y equidad social. Al romper con el paradigma de la reducción del conocimiento a las partes que lo componen, con el determinismo, la ocultación del azar y la aplicación de la lógica mecanicista a los problemas de la naturaleza y lo social, surge el pensamiento complejo que busca distinguir y reconocer lo singular y lo concreto, sin desunir y sin atomizar, en un juego dialógico entre orden, desorden, organización, contexto e incertidumbre, sin dar como verdad esa particular organización de un conjunto determinado. Desde esta nueva perspectiva se está trabajando para construir escenarios deseables de desarrollo que superen los graves problemas ambientales y prevengan otros.

La ambientalización curricular enmarcada en las anteriores consideraciones, desde los años 70, se ha propuesto generar cambios en la educación superior que lleven a transformaciones de las IES para que estén en condiciones de apoyar la transformación de la sociedad hacia perspectivas de sustentabilidad.

Los efectos del nuevo coronavirus en nuestras sociedades, particularmente en México con más de 1301249 contagiados y 117949 decesos al 19 de diciembre de 2020 (Noticieros Televisa, 2020)—, nos han mostrado la crudeza de treinta años de la era neoliberal, en donde la corrupción de las élites gobernantes arrasó con el patrimonio y la riqueza del pueblo, dejando los sistemas de salud, educativos, productivos, etc., en la mayor precariedad. Por ello, ha sido una tarea titánica la reconstrucción de los hospitales y servicios de salud para atender los crecientes contagios. De la misma manera, la recomposición económica del país será una tarea sin igual.

\footnotetext{
4 La especie humana usa varias formas para adaptarse a la naturaleza: las herramientas técnicas, la organización social y los sistemas productivos. Con ello, ha desarrollado formas simbólicas de interpretación del mundo natural con las que valora e interviene a la naturaleza.
} 
Sin embargo, esta crisis sanitaria ha propiciado una mayor conciencia de varios grupos de la sociedad, que han señalado que las tareas de la ambientalización curricular deben incluir con mayor determinación el análisis y la enseñanza de la generación y afectación de este tipo de virus en la calidad de vida de la sociedad. La aparición del virus se asocia a los estilos de consumo insustentable y al alto crecimiento de la población, entre otros.

Los jóvenes en proceso de formación en las IES - los futuros profesionales- pueden reorientar sus formas de vida y de consumo. Pueden influir en su comunidad a fin de lograr cambios hacia estilos de vida saludables que no alteren tan profundamente la naturaleza, y así disminuir el peligro de la aparición de nuevos virus.

\section{La ambientalización curricular}

En el contexto de crisis ambiental, el ejercicio profesional y, por lo tanto, las IES -en su afán de contribuir al desarrollo nacional mediante la formación de profesionales - han soslayado la previsión de la alteración de los ecosistemas y son en gran parte responsables de la problemática ambiental, debido a los contenidos y valores que trasmiten, lo que afecta la calidad de vida de los seres humanos, de las otras especies, de las actividades económicas y del desarrollo.

En la investigación que hemos venido realizando (Bravo, 2013), identificamos que la ambientalización curricular plantea la formación profesional con una visión de prevención, para superar la lógica de destruir, para construir y para remediar, como se plantea en algunas carreras ambientales.

La ambientalización curricular pretende promover la inclusión de la prevención y, aún más, la inclusión de una formación prospectiva para los profesionales en formación y el trabajo interdisciplinario, con el propósito de construir escenarios deseables de desarrollo. Ello implica el rediseño curricular - desde el estudio de las profesiones y sus campos ocupacionales- y la definición de los perfiles profesionales ambientalizados, de los planes de estudio y de las unidades de aprendizaje, entre otros aspectos.

Así, la ambientalización curricular y las investigaciones necesarias que conlleva esta tarea deberán considerar que las prácticas sociales - en particular las prácticas profesionales y los procesos educativos que están en la base de los procesos de producción-consumoforman parte de las causas de la crisis ambiental.

Por otro lado, los principios de las propuestas de sustentabilidad sintetizan las causas y focos de atención para revertir tendencias y promover la construcción de un desarrollo viable para el futuro sostenible. Podemos sintetizar estos principios de la siguiente manera:

- La naturaleza - la dinámica de la Tierra- ha propiciado la disponibilidad de medios de subsistencia, por ejemplo, los minerales no orgánicos y los hidrocarburos, pero el ritmo de las actividades de producción y consumo están rebasando las tasas de sustitución de estos recursos no renovables.

- La sobreexplotación de los bienes que ofrecen los ecosistemas está rebasando sus tasas de renovación; agravada, además, por la destrucción de los ecosistemas que sostienen la vida.

- El exceso de residuos y la destrucción de los ecosistemas imposibilitan la reincorporación de los primeros a los ciclos biogeoquímicos. 
Las diferentes alteraciones interactúan en la dinámica de la biosfera, lo que produce problemas globales como el cambio climático. A ello, se agregan la distribución desigual de los productos del desarrollo y las relaciones de inequidad entre países ricos y pobres y entre grupos al interior de los países. Esto hace necesaria la redistribución de los bienes del desarrollo y la equidad entre los seres humanos de ahora y de las futuras generaciones.

Para la ambientalización curricular, se requiere una revisión de los planes de estudio existentes en términos de sus objetivos y contenidos, para desarrollar la comprensión y la inclusión transdisciplinaria de la sostenibilidad social, económica y ambiental. No obstante, esto implicaría generar nuevas formas didácticas de aproximación al conocimiento. Para ello, se recomiendan métodos de enseñanza, de aprendizaje y de evaluación en la formación permanente, que incluyan habilidades para el pensamiento creativo y crítico, para comunicación oral y escrita, para la colaboración y la cooperación, para la gestión de conflictos, la toma de decisiones, la resolución de problemas y las experiencias de planificación, con el uso de las TIC. También se recomienda la práctica de la ciudadanía, entendida centralmente como educar a la gente para promover el consumo y producción sostenibles (Unesco, 2005).

\section{Diferentes concepciones}

En el debate sobre la ambientalización curricular, de manera inicial, en la década de los 70, se planteó la denominación de incorporación de la dimensión ambiental. Las denominaciones de ambientalización curricular y sostenibilidad curricular son más recientes. Estas denominaciones proceden de los distintos momentos en que se ha conformado el campo de la educación ambiental y han adquirido diferentes significados.

Cuando se utilizó el término dimensión ambiental, lo ambiental estaba ausente: aludía a los aspectos no tomados en cuenta en los diversos planos de la vida social, en la planeación del desarrollo, en la creación de instituciones, en los cuerpos duros de las disciplinas científicas, en las políticas públicas y, por supuesto, en la educación, entre otros. Para Sunkel (1981), la inclusión de la dimensión ambiental significa reconocer que el proceso de crecimiento económico está condicionado por el medio biofísico, local, nacional y global, porque afecta de diversas maneras el crecimiento económico y sustancialmente es afectado por él, cada vez más, mientras avanza el proceso de desarrollo.

La dimensión ambiental del desarrollo se refiere al conjunto de valores, actitudes y motivaciones que rigen las relaciones entre la sociedad y la naturaleza y las formas como dichas relaciones se traducen en los sistemas de producción y apropiación de los recursos productivos, así como en el manejo individual y colectivo de los recursos naturales, el equilibrio ecológico y la preservación y calidad de la vida. Estas relaciones, estos sistemas y estos manejos son de importancia vital tanto para la sociedad como para la naturaleza, debido a que la vida sobre el planeta y la perpetuidad de la especie humana y de todas las demás especies vivientes dependen de la racionalidad y de la responsabilidad con las cuales se entienda y se maneje la siguiente insoslayable confrontación dialéctica: por una parte, la necesidad vital e ineludible de las sociedades de asentarse, subsistir, convivir, progresar y proyectarse históricamente, a expensas de la naturaleza y sus inmensos recursos y potencialidades; y, por otra, la fragilidad y vulnerabilidad de esa naturaleza y sus flujos y ciclos ecológicos, así como la incuestionable finitud de todos sus recursos. La necesidad 
vital de conservar y de desarrollar la naturaleza y su equilibrio ecológico es una condición sine qua non de la vida orgánica, de la supervivencia y del desarrollo de toda la sociedad humana y no humana en el planeta que habitamos

La introducción de la perspectiva ambiental cuestiona una serie de creencias derivadas de la ideología del crecimiento económico que ha prevalecido en los últimos decenios, como es la del crecimiento infinito, la inagotabilidad y el autocuidado de la naturaleza, entre otras.

En la década de 1990, en la reunión de la Conferencia de las Naciones Unidas sobre el Medio Ambiente y el Desarrollo — conocida como Río 92-, se cambió la denominación de la dimensión ambiental como referente central. De manera oficial, se adoptó la denominación de desarrollo sustentable, que se acogió como la utopía socialmente compartida. Con dicha denominación, se pretendió llegar a una visión integrada del ambiente con los aspectos ecológicos, sociales, políticos, económicos, éticos y culturales. Derivado de ello, se adoptó la noción de ambientalización curricular. Esto marcó una diferencia importante, ya que dicha denominación obedecía a la idea de superar la noción de dimensión ambiental, la cual suponía que solo hacía referencia a una parte de la problemática: la parte ecológica. Se estableció como meta la inclusión de criterios del desarrollo sustentable en los planes de estudio.

La ambientalización se concibió como un proceso continuo de producción cultural tendiente a la formación de profesionales comprometidos con la búsqueda permanente de las mejores relaciones posibles entre la sociedad y la naturaleza, el cual atiende a los valores de la justicia, la solidaridad y la equidad, y aplica los principios éticos universalmente reconocidos y el respeto a las diversidades.

De esta manera, la ambientalización curricular busca contribuir a la formación de los futuros egresados, con el fin de prevenir los posibles impactos ambientales negativos derivados de su práctica profesional y, más aún, de que participen a través de dicha práctica en la construcción de los escenarios deseables del desarrollo. Ello implica una formación integral que inicia con el dominio de la profesión, el papel de esta en la sociedad y en los proyectos de sociedad en los cuales se inserta, sus posibles impactos ambientales y con el desarrollo de valores que se reflejan en las actitudes de las personas (Red ACES, 2002).

La noción más reciente - sostenibilidad curricular - se enmarca en la educación para el desarrollo sostenible. Corresponde a una nueva visión del mundo, donde cada uno tiene la posibilidad y el compromiso, mediante la educación, de establecer nuevos modelos de vida, conductas y valores para crear un futuro mejor.

Se concibe como la cualificación profesional final y la formación integral del titulado, las cuales han de constituir la base sobre la que se fundamenten y se propongan aportaciones que garanticen e impulsen la introducción del desarrollo sostenible en el currículum.

Señala que los profesionales de hoy deben tener varias capacidades, entre las que están:

- comprender cómo su actividad profesional interactúa con la sociedad y el medio ambiente, local y globalmente, para identificar posibles desafíos, riesgos e impactos;

- entender la contribución de su trabajo en diferentes contextos culturales, sociales y políticos y cómo estos afectan al mismo y a la calidad ambiental de su entorno;

- trabajar en equipos multidisciplinares, para dar solución a las demandas impuestas 
por los problemas socioambientales derivados de los estilos de vida sostenibles, al incluir propuestas de alternativas profesionales que contribuyan al desarrollo sostenible;

- aplicar un enfoque holístico y sistémico a la resolución de problemas socioambientales;

- ir más allá de la tradición de descomponer la realidad en partes inconexas;

- participar activamente en la discusión, la definición, diseño, implementación y evaluación de políticas y acciones, tanto en el ámbito público como en el privado, para ayudar a redirigir la sociedad hacia un desarrollo más sostenible;

- aplicar los conocimientos profesionales de acuerdo con principios deontológicos y valores y principios éticos universales; y

- recoger la percepción, las demandas y las propuestas de los ciudadanos para permitir que tengan voz en el desarrollo de su comunidad.

Con base en lo anterior, se vislumbra que la educación, en esta perspectiva, debe:

- tener un enfoque integrado sobre los conocimientos, las actitudes, las habilidades y

los valores en la enseñanza;

- promover el trabajo en equipos multidisciplinares;

- estimular la creatividad y el pensamiento crítico;

- fomentar la reflexión y el autoaprendizaje;

- reforzar el pensamiento sistémico y un enfoque holístico;

- formar personas participativas y proactivas que sean capaces de tomar decisiones responsables;

- adquirir conciencia de los desafíos que plantea la globalización; y

- promover el respeto a la diversidad y la cultura de la paz. (CRUE, 2005)

\section{Coronavirus: covid-19}

Ante la aparición del nuevo coronavirus a nivel mundial $-y$ de los futuros virus que se anuncian (Carabias, 2020) - , la ambientalización curricular adquiere nuevas perspectivas y una urgente atención. Es de suma importancia que las actuales y las nuevas generaciones aprendan a cultivar un consumo pertinente y a adquirir una conciencia de la prevención. Por ello, estos temas deben estar presentes en el currículum de la educación superior y/o en la formación extracurricular de los estudiantes y maestros, y, en general, en la comunidad educativa de cada institución.

Se ha señalado que este virus ha dividido nuestra historia en dos - antes y después de él一, por lo que ahora tendremos que vivir de manera diferente en un largo plazo (Cepal, 2020). En consecuencia, la ambientalización curricular necesita ubicarse ante este fenómeno y propiciar una mayor formación sobre la situación, sin desatender el panorama de la crisis ambiental que vivimos (Cepal, 2020).

Ante la pandemia del covid-19, nos hacemos varias preguntas:

- ¿La crisis por el coronavirus es un signo de crisis capitalista o es un signo de una crisis de civilización?

- ¿La vida en las ciudades nos ha alejado de la propia naturaleza?

- ¿Hemos dejado de coevolucionar con ella?

- ¿Por ello las altas afectaciones a la salud humana?

Por su parte Leff (2020) se pregunta: 
- ¿Qué es un virus?

- ¿Cómo es que, siendo parte de la evolución de la vida, se convierte en un agente mortífero que ataca y destruye la vida?

- ¿Cuál es su función en la evolución de la vida?

- ¿Qué agencia - de la propia naturaleza o de la intervención humana- activa su diseminación y sus efectos patógenos?

Lo cierto es que hay desconocimiento para responder estas y otras preguntas, por lo que debemos propiciar una conciencia de la prevención y promover la investigación en estos aspectos a partir de lo que se conoce.

\section{Interacción y cambio}

La sociedad, la cultura, los ecosistemas, la Tierra, el sistema solar y el universo son producto de la interacción y el cambio de sus componentes. El origen de la vida y su evolución - desde las primeras células hasta las aves y los mamíferos- son historias de interacción y cambio, de integración en diferentes niveles de complejidad y de la emergencia de propiedades nuevas en cada nivel de agregación.

El origen y la evolución biológica del homo sapiens, su evolución sociocultural y sus impactos ambientales son también producto de la interacción y el cambio. La interacción, el cambio, la integración en diferentes niveles de complejidad y la emergencia de propiedades son rasgos comunes de los fenómenos naturales y sociales. No obstante, los procesos de cambio naturales se han producido en escala de tiempo geológico.

El hombre, con todas sus características modernas, existe desde hace 40000 años, pero el impacto del ser humano en la naturaleza ha sido de mayor magnitud en los últimos 300 años. Así, mientras que los cambios de los fenómenos naturales se producen en escalas de tiempo geológico, los cambios provocados por los seres humanos son de gran magnitud y se producen en lapsos de cientos o decenas de años. Por ello, los seres humanos y sus acciones se consideran una fuerza de cambio de gran magnitud que puede causar su propia extinción como especie.

Históricamente, la sociedad se ha apropiado de la naturaleza y la modifica. El medio natural ha sido fuente determinante en la cosmovisión e identidad de las culturas. Es decir, los seres humanos hemos coevolucionado con la naturaleza desde nuestra aparición en la Tierra.

Sin embargo, a causa del poderío tecnológico y del crecimiento exponencial de la especie humana, hemos explotado la naturaleza más allá de los límites físicos que se habían valorado para no causar mayores desequilibrios. Tanto el consumo como el uso de la energía y de los recursos que se utilizan han propiciado el cambio climático y efectos negativos en los sistemas ecológicos. Se ha incrementado de manera intensa el dióxido de carbono $-\mathrm{CO}_{2}-$ en la atmósfera. Hoy tenemos 414 partes por millón, contra las 280 partes de antes de la Revolución industrial (Brito \& Stafford, 2012).

Desde hace varios años, hay una gran preocupación por los impactos negativos sobre la Tierra, ya que estos están siendo de gran magnitud. Se ha demandado la urgencia de reducir la emisión de los gases de efecto invernadero para frenar un cambio climático, que ya causa el sufrimiento de muchos seres humanos y de otras especies en el planeta; 
un cambio climático que también puede acelerar la llegada de enfermedades como la que estamos sufriendo. Por el cambio climático, virus y bacterias ahora están en zonas donde antes no existían.

La pérdida de biodiversidad es otro de los problemas globales ambientales preocupantes. Esta se relaciona con el cambio de uso del suelo para la producción alimentaria, que ha propiciado la defaunación, la cual es impactante a causa de la pérdida de selvas y bosques. Todo está involucrado en un sistema que ya es insostenible, donde, además del daño ecológico, tenemos daños a la salud humana. Vivimos en un planeta finito y no podemos pretender modificar las leyes de la naturaleza a nuestro antojo para ajustarlas a nuestras concepciones de desarrollo económico o financiero. Al contrario, deberíamos modificar nuestro desarrollo según las leyes de la naturaleza.

\section{Desequilibrio de la naturaleza}

Si seguimos presionando los ecosistemas naturales con un consumo exacerbado de recursos y de territorio, podemos propiciar focos de contagio. Podemos perder la capacidad de resistir el embate de eventos climáticos extremos. Perderemos, en definitiva, nuestra capacidad de resiliencia como sociedad.

Se está afectando la función protectora de la biodiversidad que, gracias a efectos como la dilución de la carga vírica y la amortiguación del contagio, es una inmensa y eficaz barrera para las zoonosis, como lo es el coronavirus.

El SARS-CoV-2 ha coevolucionado largo tiempo con el murciélago de forma que cuando está sano, la carga vírica es mínima (Valladares, 2020; Toledo, 2020). En estados de estrés, como cuando se le persigue, se caza, se manipula y se consume, el sistema inmune del animal se deprime y la carga vírica se dispara.

Les ocurre algo similar a los demás hospedadores como el pangolín, objeto de caza y de tráfico ilegal en muchas regiones de Asia y de África, donde demandan su carne como alimento y sus escamas de queratina - como nuestras uñas- para usarlas en medicinas tradicionales orientales. Estos son los mamíferos silvestres más cazados y traficados del mundo. En tal situación, con el hospedador inmunodeprimido que alcanza una alta carga vírica, el virus resulta más peligroso para el ser humano.

Si a ello le agregamos que las sociedades humanas también hemos experimentado los problemas ambientales por muchos años y que hemos vivido con elevadas tasas de contaminación atmosférica en ciudades, como las del norte de Italia, Madrid o Ciudad de México - con graves consecuencias para la salud, especialmente en poblaciones vulnerables-, se podría decir que esto tiene relación con una mayor incidencia de enfermedades cardiorrespiratorias como el covid-19.

Una naturaleza sana, con ecosistemas funcionales y ricos en especies, nos protege de una manera muy amplia ante infecciones por patógenos. La naturaleza, en general, nos protege del polvo del desierto y ayuda a reducir la contaminación atmosférica, dos vehículos que propagan virus y que acentúan los síntomas respiratorios en los pacientes afectados por el covid-19.

Lo que resulta indiscutible es que son nuestros hábitos y comportamientos los que nos 
ponen en peligro, porque detrás de esta pandemia está la destrucción de la naturaleza que hemos propiciado.

La gran mayoría de ambientalistas coincide en que han sido las prácticas de producción agropecuarias, en el marco del neoliberalismo, lo que ha desatado el ataque de este virus, $y$, de seguir así, podrían seguir muchos más, aún desconocidos y letales (Zibechi, 2020).

\section{La producción agropecuaria}

Se ha identificado que una de las causas estructurales de este patógeno - el coronavirusy de otros más ha sido el proceso de producción de alimentos y la rentabilidad de las empresas multinacionales en tiempo del neoliberalismo (Altieri \& Nichols, 2020). El modelo industrial de la agricultura ha generado que los virus sean cada vez más nocivos. Sin embargo, esto no se ha investigado, ya que, ante la aparición de un nuevo patógeno, lo que hacen es buscar la nueva cura o vacuna, de donde se obtienen grandes ganancias.

Pero la situación es más amplia y preocupante. El neoliberalismo salvaje ha encabezado el acaparamiento de las tierras, de los últimos bosques primarios, y las explotaciones agrarias a los pequeños propietarios a nivel mundial. Con ello se ha producido la deforestación y la aparición de nuevas enfermedades. El arrasamiento de las tierras ha propiciado la liberación de los patógenos que antes estaban encerrados, los cuales migran a la ganadería local y a las comunidades humanas.

En México, el libre comercio devastó el campo, arruinó a pequeños y medianos agricultores y obligó a millones de pequeños campesinos a migrar a los Estados Unidos o al noroeste del país. Y no solo eso, trastocó profundamente la dieta de las clases populares al provocar lo que ahora sale a relucir con el covid-19, otras graves epidemias: la de obesidad, la de desnutrición y la de diabetes, lo que aumenta la mortalidad de los mexicanos contagiados por el coronavirus.

El ébola, el zika, otros coronavirus, la reaparición de la fiebre amarilla, una variedad de gripes aviares y la peste porcina africana se encuentran entre muchos de los patógenos que salen de las zonas más remotas del interior hacia los circuitos periurbanos, las capitales regionales y, finalmente, hacia la red mundial de viajes. No hay patógenos libres de la influencia del capital. Incluso las regiones más remotas se ven afectadas, aunque sea desde la lejanía. Con los acercamientos mundiales, en pocas horas o semanas, puede llegar del Congo el virus del ébola a los bañistas de Miami, que fallecen a causa de este.

Desde hace algunos años, se calculó que la naturaleza podría ser una gran inversión económica, por lo que hoy el planeta Tierra, en gran parte, es una gran fábrica agrícola industrial, tanto en términos de biomasa como de uso de la tierra. La agroindustria tiene como objetivo acaparar el mercado de alimentos. El proyecto neoliberal está diseñado para ayudar a las empresas de los países industrializados más desarrollados a robar tierras y recursos de los países más débiles. Como resultado, muchos de estos nuevos patógenos, previamente ligados a ecosistemas forestales que se habían desarrollado durante largos periodos de tiempo, están siendo liberados y amenazan al mundo entero.

Las necesidades capitalistas, en sustitución de la ecología natural, organizan la agricultura y proporcionan los medios exactos por los que un patógeno puede desarrollar los fenotipos más virulentos e infecciosos. No se podría diseñar un mejor sistema para 
generar enfermedades mortales, pero a ellos no les importa que la gente muera.

La agroindustria está orientada a utilizar los beneficios de los virus sin importar la mortalidad humana que genera, siempre y cuando sus ganancias no se vean afectadas. La expansión de los monocultivos genéticos de animales de granja elimina cualquier barrera inmunológica que pueda estar disponible para ralentizar o frenar la transmisión. Las grandes dimensiones y las altas densidades de población facilitan mayores tasas de transmisión. Estas condiciones de hacinamiento deprimen la respuesta inmunológica de los animales. El alto rendimiento de los animales, como parte indisoluble de cualquier producción industrial, proporciona a los virus un suministro constante de nuevos animales huéspedes, lo que promueve su virulencia.

La producción de alimentos altamente industrializada depende de prácticas que ponen en peligro a toda la humanidad y, en este caso, es posible que contribuya a desencadenar una nueva pandemia mortal, gracias al incremento del consumo de conservantes peligrosos causantes de muchas enfermedades, que además generan pandemias como la obesidad que ahora padecemos en México.

\section{Tareas para la ambientalización curricular}

Varias son las tareas que nos deja esta experiencia, la cual aún no termina y no sabemos cuándo vaya a finalizar. Tal vez el virus sea parte de nuestra vida futura, como lo ha sugerido el sector salud.

Si las causas de la aparición de esta enfermedad se pueden encontrar en la rápida urbanización, en los cambios en los sistemas agropecuarios, en cambios en los ecosistemas y en una mayor globalización del tráfico de animales y de sus productos, es necesario cambiar de fondo nuestras prácticas sociales, nuestro consumo, nuestra relación con la naturaleza, lo cual ya se ha mencionado desde hace varios años. Este podría ser uno de los últimos avisos de la naturaleza.

Las universidades en estos temas tienen un amplio panorama de acción, formación y educación en una cultura de sustentabilidad, que implica reorientar el consumo racional, adecuar la producción agropecuaria, fortalecer y aplicar la normatividad ambiental para inhibir el tráfico y consumo de animales de vida silvestre, más aún ante la sexta extinción, que está en marcha.

El límite de la capacidad del ecosistema de la Tierra no puede seguir ampliándose. El crecimiento de la población es uno de los importantes retos que debe modificar la humanidad. La orientación de las universidades en su comunidad debe promover un crecimiento poblacional racional.

El responsable, de manera más amplia, es un sistema social, una civilización, en la que una minoría de menos del $1 \%$ de la población explota por igual tanto el trabajo de la naturaleza como el trabajo de los seres humanos. La desigualdad social y ambiental está en el centro de muchos problemas actuales. Las universidades tienen como misión disminuir la desigualdad social, por lo que deberán buscar nuevas formas eficaces para equilibrar la vida de las poblaciones.

Se ha propuesto el paso de una economía de mercado a una economía social y solidaria; de grandes empresas y corporaciones a empresas familiares y cooperativas - fin de los 
monopolios-, de gigantescos bancos a cajas colectivas de ahorro; de energía fósil a energías renovables; de sistemas agroalimentarios industriales a sistemas agroecológicos; de organizaciones centralistas y verticales a organizaciones descentralizadas y horizontales -redes-; de una democracia representativa a una democracia participativa. Pero, sobre todo, se ha propuesto construir desde lo local - comunidades, municipios, microrregionesun poder ciudadano o social capaz de enfrentar y controlar las acciones suicidas del capital. En suma, una ecopolítica desde, con y para la vida. La búsqueda del bien común en los mecanismos de desarrollo social es una tarea inaplazable en que las universidades pueden apoyar fuertemente.

Deberíamos exigir que los sistemas alimentarios se socialicen, de tal manera que estos patógenos peligrosos no puedan desarrollarse. Para lograr esto, se requerirán, en primer lugar, prácticas agroecológicas que protejan el medio ambiente y a los agricultores que cultivan los alimentos. En el panorama general, necesitamos curar la grieta metabólica que separa nuestra ecología de nuestra economía.

En un mundo interrelacionado como el actual se ha incrementado la posibilidad de que aparezcan y se expandan rápidamente enfermedades infecciosas emergentes y reemergentes. Este riesgo tiene su origen en varios factores, como la aparición de nuevos patógenos, la facilidad de circulación de personas y alimentos, el aumento de microorganismos resistentes a determinados medicamentos, los avances en el ámbito de la biotecnología y la adquisición de agentes patógenos por parte de grupos terroristas.

Las consecuencias de la expansión de una enfermedad infecciosa pueden llegar a ser catastróficas, no solo al afectar la salud y economía de la población, sino también la economía mundial y la estabilidad del país en donde se producen, como lo estamos observando.

La pandemia nos muestra con crudeza cuán sensibles somos a un medio natural que no funcione bien. La situación actual debería servir de ensayo para repensar una gran crisis que nos está esperando, que no cesa y que es aún más compleja de gestionar y atajar que la pandemia del coronavirus: la del cambio climático y la de la pérdida de la biodiversidad.

La conservación de la salud a través de la alimentación y el consumo sustentable son puntos neurálgicos que deberán incluirse, ya sin demora, en los procesos educativos y en la ambientalización curricular. Lo que tenemos que hacer es perfilar una nueva relación más equilibrada con la naturaleza y sostenible en el tiempo. Es necesario cuestionar profundamente el marco social y económico en el que nos movemos.

En todo este tiempo, la asistencia sanitaria a los enfermos ha funcionado, pero en condiciones heroicas. Tenemos que lograr que, a partir de ahora, funcione en condiciones soportables, sin bordear el colapso. La seguridad higiénica ambiental deberá ser una tarea en la que las universidades aporten no solo con la formación de personal del sector de la salud, sino con la generación de medicinas y tecnologías de cuidado y autocuidado, tecnologías necesarias para la procuración de la salud.

Debemos aprender que lo realmente importante es planificar, ampliar sustancialmente y desplegar rápido las armas de la salud pública, además de orientarlas a la supresión de los contagios y no solo a su mitigación, ahora y en el futuro; en suma, estar preparados por si llega una nueva ola de contagios. 
En el mediano plazo, parece inaplazable la reforma de nuestro Sistema Nacional de Salud con solvencia técnica y sabiduría política. Nuestros profesionales de la salud se merecen algo más que aplausos y una subida de sueldo.

Las universidades del país deben ser partícipes de estas grandes tareas que nos ha dejado la experiencia de la pandemia del covid-19 - no solo nos referimos a los estudiantes del sector salud, sino a la universidad en su conjunto-. Ya que el problema es global, así debe buscarse su solución.

\section{Referencias}

Altieri, A. \& Nichols, C. (2020) (2020). La agroecología en tiempos del covid-19. Universidad de California; Clacso.

Bravo, M. (2013). La dimensión ambiental y su incorporación en el currículum de la Universidad Nacional Autónoma de México. UNAM.

Brito, L., \& Stafford. (2012). Declaración del Estado del Planeta. Programas de investigación del cambio climático global. Consejo Internacional para la Ciencia.

Carabias, J. (2020) "El Medio Ambiente después de la crisis sanitaria". En: Cambiar el Rumbo: El desarrollo tras la pandemia. Cordera, R. y Provencio, E. UNAM México (pp 168-173) http://www.pued.unam.mx/opencms/publicaciones/42/cambiar.html

Carabias, J. (2020). El Medio Ambiente después de la crisis sanitaria. En R. Cordera, \& E. Provencio (Coords.), Cambiar el Rumbo: El desarrollo tras la pandemia (pp 168-173). UNAM. http://www.pued.unam.mx/opencms/publicaciones/42/cambiar.html

Cepal. (2020). América Latina y el Caribe ante la pandemia del COVID-19. Efectos económicos y sociales. Informe especial COVID-19, folleto 2.

CRUE. (2005). Directrices para la Sostenibilización Curricular. Comité Ejecutivo del Grupo de Trabajo de Calidad Ambiental y Desarrollo Sostenible de la Conferencia de Rectores de Universidades Españolas.

Leff, E. (2020). A cada quien su virus. La pregunta por la vida y el porvenir de una democracia viral. HALAC - Historia Ambiental, Latinoamericana y Caribeña, 5, 139-175. http:// halacsolcha.org/index.php/halac30.

Noticieros Televisa. (19 de diciembre, 2020). Conferencia Covid-19 en México - 19 de diciembre 2020 [Video]. Youtube. https://www.youtube.com/watch?v=2sw4VG9rhwg

Morin, E., \& Kern, A. (1993). La agonía planetaria. Ediciones del Sol.

Red ACES. (2002). Programa de Ambientalización Curricular de los estudios superiores. Diseño de intervenciones y análisis del proceso. Primer Encuentro de Trabajo de la Red.

Sunkel, O. (1981). La dimensión ambiental en los estilos de desarrollo de América Latina. Pnuma, Cepal.

Toledo, V. (1996). Latinoamérica: crisis de civilización y ecología política. Gaceta Ecológica, (38), 12-22. 
Toledo, V. (7 de abril,2020). El último llamado de la naturaleza. La Jornada. https://www. jornada.com.mx/2020/04/07/opinion/022a2pol

Tommasino, H, Foladori, G, \& Taks, J. (2001) La crisis ambiental contemporánea. En N. Pierri, \& F. Guillermo (Eds.), ¿Sustentabilidad? Desacuerdos sobre el desarrollo sustentable (pp. 9-26). Trabajo y Capital.

Valladares, F. (2 de abril, 2020). Si no sanamos el clima, volveremos a enfermar. The Conversation. https://theconversation.com/si-no-sanamos-el-clima-volveremos-aenfermar-13509

Unesco. (2005). Decenio de las Naciones Unidas de la educación para el desarrollo sostenible (2005-2014). Proyecto del Plan de Aplicación Internacional.

Zibechi, R. (10 de abril, 2020). Pandemia y colapso civilizatorio. La Jornada. https://www. jornada.com.mx/2020/04/10/opinion/021a1pol 